\title{
EPIDEMIOLOGY OF ORTHOPEDIC INJURIES IN JIU-JITSU ATHLETES
}

\section{EPIDEMIOLOGIA DAS LESÕES ORTOPÉDICAS EM ATLETAS PRATICANTES DE JIU-JITSU}

\author{
Alexandre Pedro Nicolini ${ }^{1}$ (i), Nathália Abolis Penna ${ }^{1}$ (i), Gabriel Taniguti de Oliveira ${ }^{1}$ (i), Moises Cohen ${ }^{1}$ (i)
}

1. Universidade Federal de São Paulo, Paulista School of Medicine, Sports Traumatology Center, São Paulo, SP, Brazil.

\section{ABSTRACT}

Objective: This study aims to identify the epidemiology of orthopedic injuries in jiu-jitsu practitioners. Methods: Ninety-six jiu-jitsu practitioners aged between 18 and 45 years, male and female, answered a questionnaire addressing personal data and history of injuries related to the sport during the last 24 months. Results: In the period cover, $85 \%$ of the sample presented injuries related to the practice of jiu-jitsu, with an average of 60 days of absenteeism from sports practice. Fingers, shoulders, and knees were the joints most affected by orthopedic injuries. Conclusion: Orthopedic injuries are quite prevalent among jiu-jitsu practitioners, often distancing athletes from the sport. Level of Evidence IV, case series / cross sectional study.

Keywords: Athletic Injuries. Martial Arts. Epidemiology.

\section{RESUMO}

Objetivo: Este estudo tem como objetivo identificar um perfil epidemiológico das lesões ortopédicas presentes em praticantes da modalidade jiu-jitsu. Métodos: 96 praticantes de jiu-jitsu, entre 18 e 45 anos, de ambos os sexos, responderam a um questionário que abordou dados pessoais e histórico de lesões relacionadas à prática do esporte nos últimos 24 meses. Resultados: 85\% da amostra apresentou lesão relacionada à prática do jiu-jitsu no período abordado, com média de 60 dias de absenteísmo da prática esportiva. Os locais mais acometidos por lesões ortopédicas foram: dedos, ombros e joelhos. Conclusão: As lesões ortopédicas são bastante prevalentes na prática do jiu-jitsu, muitas vezes afastando os atletas de sua prática. Nível de evidência IV - série de casos / estudo transversal.

Descritores: Traumatismos em Atletas. Artes Marciais. Epidemiologia.

Citation: Nicolini AP, Penna NA, Oliveira GT, Cohen M. Epidemiology of orthopedic injuries in jiu-jitsu athletes. Acta Ortop Bras. [online]. 2021;29(1):49-53. Available from URL: http://www.scielo.br/aob.

\section{INTRODUCTION}

Jiu-jitsu originated during feudal times in Japan as an art based on throwing, hitting, kicking, striking, choking, twisting members, and immobilizing the opponent. However, only after the second half of the $16 \mathrm{~h}$ century jiu-jitsu began to be practiced and taught in a systematized manner. Many Japanese migrated to the West after World War I, especially to Brazil, spreading jiu-jitsu throughout the country; since then, jiu-jitsu has been a widely spread and practiced martial art. Currently, jiu-jitsu is worldwide known as Brazilian jiu-jitsu and represented by the International Brazilian Jiu-Jitsu Federation (IBJJF). Athletes are divided according to belts (graduation), age group, and weight. Fighting time is determined based on combatants' belt and category. Within the adults category (18 to 29 years), fighting time ranges from 5 to 10 minutes according to belt. In the Master category, fighting time is 5 minutes regardless of belt. In jiu-jitsu, the goal is to finish the fight using projections, chokes, twists, and immobilizations, often with joint blockage, which may result in various types of lesions, predominantly orthopedic. ${ }^{1-5}$
These fights are characterized by unexpected, fast, repetitive, and high-intensity effort movements, subjecting joints and muscles to an intense overload. Added to the large number of competitions and training intensity, these factors incur in many musculoskeletal injuries. ${ }^{5}$ Many epidemiological studies in the world literature investigate injuries suffered in various martial arts, such as judo, karate, taekwondo, and mixed martial arts (MMA). However, studies associating injuries with jiu-jitsu practice are still scarce. Studies show that the incidence of musculoskeletal injuries associated with jiu-jitsu practice is similar to that found for other martial arts, and that knees, elbows, and other joints commonly subjected to the torsional mechanism are the most common injury sites. ${ }^{2,3,5}$

Studies that assess various modalities epidemiology and compare injuries incidence among them on competitions such as the Olympics and high school and university championships are fairly common in the literature. ${ }^{6-9}$ And, although these studies do not include jiu-jitsu, they serve as basis for comparing the epidemiology of other modalities, including fights as judo and wrestling. ${ }^{2-7,10-12}$

All authors declare no potential conflict of interest related to this article.

The study was conducted at the Universidade Federal de São Paulo, Paulista School of Medicine, Sports Traumatology Center. Correspondence: Alexandre Pedro Nicolini, Rua Estado de Israel, 636, São Paulo, SP, Brazil, 04022001. apnicolini@uol.com.br 
Musculoskeletal injuries account for about $80 \%$ of sports injuries. Thus, the number of orthopedic injuries has increased alongside the exponential increase in sports practice by the general population (including at age groups extremes). ${ }^{12-14}$

Many are the categories attributed for sports injuries, such as: those that lead to the interruption of sports practice and/or competitions, those that lead to a decrease in activity level, or those that require treatment, whether surgical or non-surgical. Injuries may be classified according to their severity, absence period from sports practice, length of treatment, nature of the injury, and injury profile (type), ${ }^{13-15}$ indicating that understanding sports injuries helps to predict and prevent future injuries..$^{8,15}$

Most musculoskeletal injuries are minor contusions, sprains, and muscle injuries (54\%) that entail but a short absence from activities. ${ }^{12-16}$ This study aims to identify the epidemiology of orthopedic injuries in jiu-jitsu practitioners. Epidemiological studies are extremely important for establishing literary data, developing preventive methods, comparing sports modalities, and even implementing or changing rules.

\section{MATERIALS AND METHODS}

\section{Study design}

This is a questionnaire-based cross-sectional study conducted with jiu-jitsu practitioners over 18 years old. The questionnaire (Appendix 1) collected personal data and history of orthopedic injuries related to the sport in the last 2 years through questions addressing the number of injuries, affected site, whether injuries occurred during training or competition, and the treatment received. This project was approved by the Ethics and Research Committee of the Universidade Federal de São Paulo - UNIFESP (opinion no: 52533815.2.0000.5505).

All participants signed the informed consent form. Data was collected using the Referred Morbidity survey, tested by Pastre et al. ${ }^{17}$ and validated for the modality at stake.

\section{Participants}

Male and female jiu-jitsu practitioners for at least 12 months, from different training centers in the Metropolitan Region of São Paulo from October to December 2019, and over 18 years of age were considered eligible for the study.

\section{Inclusion criteria}

Male and female jiu-jitsu practitioners for at least 12 months, aged between 18 and 45 years, and with a minimum training frequency of twice a week were included in the study.

\section{Exclusion criteria}

Individuals outside the stipulated age range, practicing jiu-jitsu for less than 12 months and less than twice a week, who had recently undergone surgical procedure and returned to the practice within 1 year of the evaluation were excluded from the research.

In total, 96 practitioners answered the questionnaire, 82 males and 14 females.

\section{RESULTS}

The initial analysis concerns participants' data (Table 1).

Regarding gender, $85 \%$ of the participants were male and $15 \%$ female. The sample average age was 27.65 ( \pm 1.42 ).

As for athletes' graduation, we observed the following distribution:
Table 1. Representativeness of graduation.

\begin{tabular}{c|c|c}
\hline Belts & Athletes & \\
\hline White & 25 & $26 \%$ \\
\hline Blue & 25 & $26 \%$ \\
\hline Purple & 16 & $17 \%$ \\
\hline Brown & 9 & $9 \%$ \\
\hline Black & 21 & $22 \%$ \\
\hline Total & 96 & $100 \%$ \\
\hline
\end{tabular}

Table 2 show practitioners' training frequency, with an average frequency of 3.56 training sessions/week $( \pm 0.31)$.

\begin{tabular}{c|c|c} 
Table 2. Description of weekly training frequency. \\
\hline Frequency training sessions/week & & $27 \%$ \\
\hline 2 & 26 & $18 \%$ \\
\hline 3 & 17 & $13 \%$ \\
\hline 4 & 13 & $19 \%$ \\
\hline 5 & 18 & $7 \%$ \\
\hline 6 & 7 & $3 \%$ \\
\hline 7 & 3 & $3 \%$ \\
\hline 8 & 3 & $4 \%$ \\
\hline 9 & 4 & $4 \%$ \\
\hline 10 & 4 & $1 \%$ \\
\hline 11 & 1 & $100 \%$ \\
\hline Total & 96 &
\end{tabular}

Table 3 shows the results of competitions annual frequency.

\begin{tabular}{c|c|c} 
Table 3. Yearly number of competitions. \\
\hline Competitions frequency & $\mathbf{n}$ & $\%$ \\
\hline Not reported & 25 & $26 \%$ \\
\hline None & 19 & $20 \%$ \\
\hline 1 & 10 & $10 \%$ \\
\hline 2 & 14 & $15 \%$ \\
\hline 3 & 1 & $1 \%$ \\
\hline 4 & 5 & $5 \%$ \\
\hline 5 & 5 & $5 \%$ \\
\hline 6 & 5 & $5 \%$ \\
\hline 8 & 4 & $4 \%$ \\
\hline
\end{tabular}

Eighty-one participants (84\% of the sample) suffered some type of orthopedic injury in the last 2 years (Figure 1), totalizing 229 injuries. Of these, 69 were male (84\%) and 12, female (86\%).

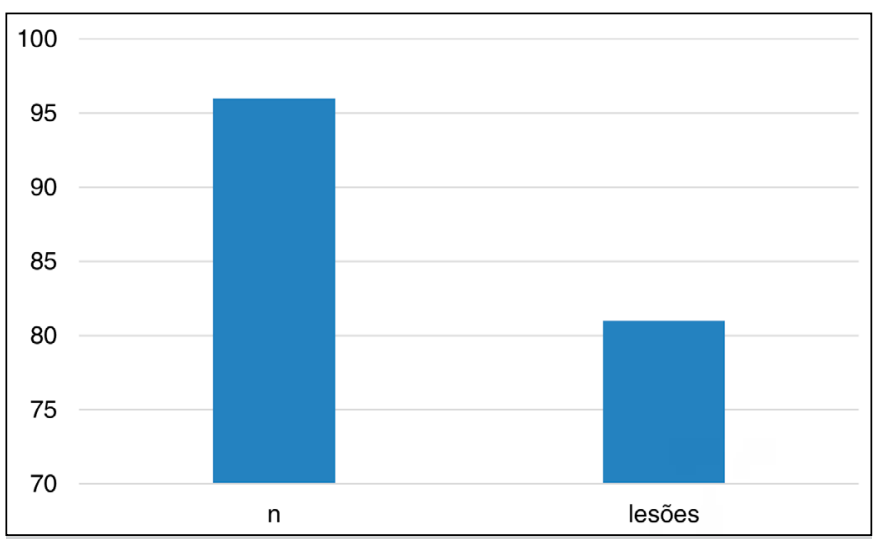

Figure 1. Number of participants who reported orthopedic injuries.

With that, we analyzed the moment at which injury occurred and which anatomical region was affected. Regarding affected site, we found the following distribution (Table 4): 
Table 4. Injury site

\begin{tabular}{c|c|c|c}
\hline Table 4. Injury site & Male & Female & Total \\
\hline Site & 4 & 2 & 6 \\
\hline Cervical spine & 2 & 1 & 3 \\
\hline Thoracic spine & 12 & 5 & 17 \\
\hline Lumbar spine & 44 & 11 & 55 \\
\hline Chirodactyls & 11 & 2 & 13 \\
\hline Wrist & 16 & 5 & 21 \\
\hline Elbow & 37 & 4 & 41 \\
\hline Shoulder & 7 & 0 & 7 \\
\hline Hip & 32 & 5 & 37 \\
\hline Knee & 19 & 3 & 22 \\
\hline Ankle & 5 & 2 & 7 \\
\hline Pododactiles & 189 & 40 & 229 \\
\hline Total & &
\end{tabular}

Chirodactyls were the most injured site during jiu-jitsu practice, with $24 \%$ of total injuries, followed by shoulder, knee, and ankles (Figure 2).

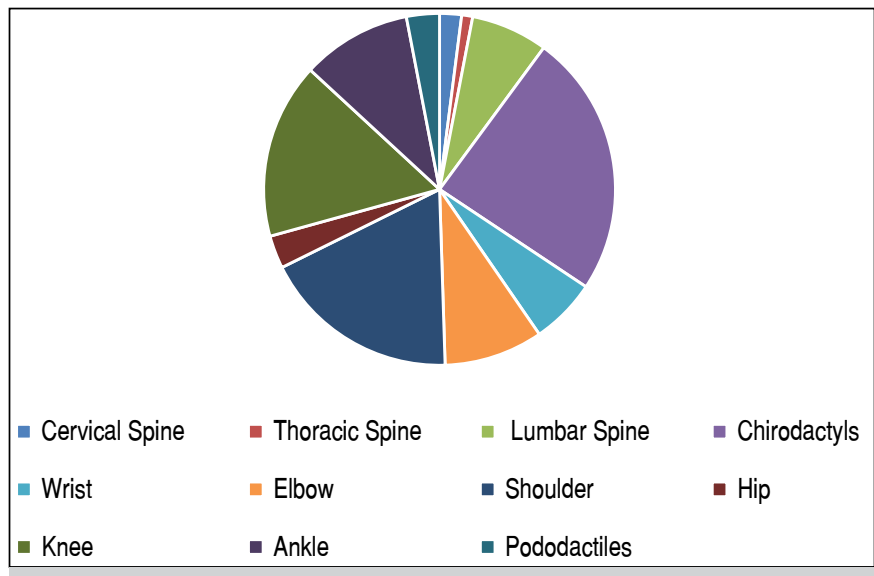

Figure 2. Percentage of affected sites.

Regarding the moment of injury, practitioners reported whether it occurred during training or competition, and injuries during training were more common than those occurred during competitions, as shown in Figure 3.

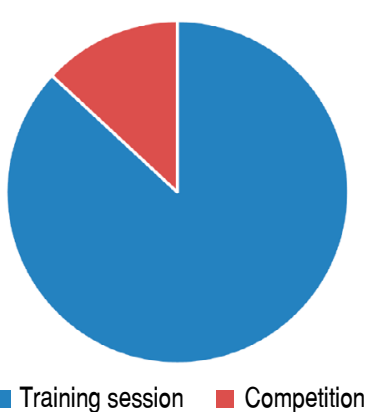

Figure 3. Injuries distribution according to the moment.

After investigating lesions and most affected anatomical regions, we studied treatment approaches. The first variable concerned the search for medical intervention.

Only $65 \%$ of the practitioners who got injured in the last 24 months sought medical attention. Among the $35 \%$ who did not, $21 \%$ reported self-treatment (Figure 4).

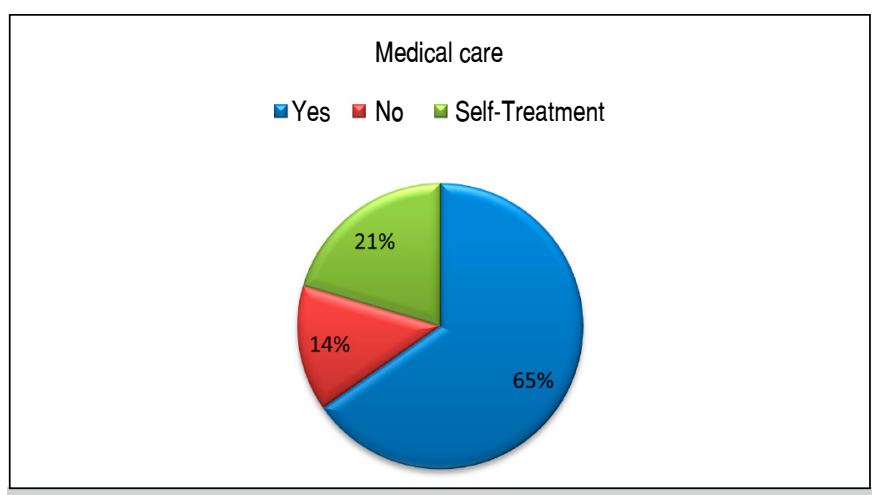

Figure 4. Search for medical care.

As for received medical treatment, we obtained the following distribution (Table 5):

Table 5. Received medical treatment.

\begin{tabular}{c|c}
\hline Performed procedure & $\mathbf{n}$ \\
\hline Surgery & 4 \\
\hline Immobilization & 11 \\
\hline Physical therapy & 21 \\
\hline Medication & 18 \\
\hline
\end{tabular}

Table 6 shows data on subjects who performed self-treatment.

Table 6. Self-treatment performed.

\begin{tabular}{c|c}
\hline Treatment & $\mathbf{n}$ \\
\hline Immobilization & 7 \\
\hline Physical therapy & 5 \\
\hline Medication & 12 \\
\hline
\end{tabular}

Average absenteeism period was $63.33( \pm 4.48)$ days among men and 58.63 ( \pm 8.40) among women.

Regarding post-injury return to sports, $22 \%$ of practitioners reported returning at the same or higher level than pre-injury, $60 \%$ reported returning at a level lower level, and approximately $18 \%$ did not inform.

\section{DISCUSSION}

Among the 96 practitioners who answered the questionnaire, 13 men and two women reported having suffered no injury during jiu-jitsu practice in the last 2 years, whereas 81 participants had at least one orthopedic injury - a significant percentage. These injuries incur long periods of sport absence and loss of training, physical fitness, and even financial resources for professional athletes.

In our sample, chirodactyls, shoulder, knee, ankle, elbow, and lumbar spine were the most affected sites, which may be explained by the movements mechanics and strikes inherent to jiu-jitsu. Chirodactyl injuries are quite common due to kimono grips, strikes, and blocks. Shoulder and elbow injuries are due to falls and armlocks, which may place the elbow in hyperextension positions and/or adduction-abduction stress. Knee injuries are quite common after falls, opponents' falls over one's knee, "guard pass," and in kicking/ tripping someone. ${ }^{2}$ Cervical spine is usually compromised after choke and post-fall direct trauma, ${ }^{18}$ whereas ankle injuries usually occur after "foot lock." Pododactile injuries are also common after torsional trauma on the mat. ${ }^{2}$

Epidemiological studies are required to understand the mechanisms of injury, most prevalent injuries, most affected anatomical regions, as well as treatments received and absenteeism length related to the practice of jiu-jitsu. This enable better preventive and treatment conducts for reinserting the athlete into sports practice 
in a more agile manner, without functional impairments and with low risk of recurrence. Given this is a questionnaire-based study and athletes/patients may lack the knowledge on injury type, we did not evaluate this variable.

Injuries suffered during training were more prevalent than those suffered at competitions, which is justified by the greater number of practicing hours during the week and even greater during training sessions (one or more hours), whereas competition fights last from 2 to 10 minutes. The longer the exposure/practice time within the same session, the greater the risk of injury. ${ }^{9,16}$ Some authors explain that competition injuries tend to differ from those suffered during training, given that in competitions athletes often seek victory by submission. Such submission may result in injuries, especially when the opponent does not "hit" by surrender. ${ }^{19}$

Epidemiological studies approaching injuries in the practice of jiu-jitsu are still scarce in the literature. Scoggin et al. ${ }^{2}$ conducted one of the most important studies on the subject, assessing injuries suffered during a jiu-jitsu championship between 2005 and 2011. The authors reported an incidence of 9.2 injuries per 1000 fights, with a high prevalence of orthopedic injuries (78\% of injuries). They also found elbow to be the most affected site, which may be explained by the bar movement, quite common in the sport.

Kreiswirth et al. ${ }^{3}$ evaluated 951 athletes during a jiu-jtsu championship and reported 62 injuries, 40 of which in joints. They found black belt athletes to present a higher incidence of injuries, most commonly affecting the knees, elbows, and ankles.

In a retrospective study conducted with medical records and charts, Stephenson and Rossheim ${ }^{5}$ found 39,181 injuries between 2008 and 2015 related to the practice of jiu-jitsu, judo, and mixed martial arts (MMA) in the United States. The authors found sprains to be the most common type of injury in jiu-jitsu and, corroborating our findings, injuries occurred predominantly during training. Head, hands, shoulder, and feet were the most common affected sites.

McDonald et al. ${ }^{19}$ conducted a similar questionnaire-based study and obtained 166 answers from jiu-jitsu practitioners. They found hands and fingers, feet, elbows, and shoulders to be the most common affected sites, corroborating our results.

When comparing jiu-jitsu with other fighting modalities, a study addressing injuries caused by judo found chirodactyls and knees to be the most common affected sites, similar to our findings. ${ }^{19}$ Petrisor et al. ${ }^{4}$ conducted a questionnaire-based study with 70 jiu-jitsu practitioners to establish the epidemiology of injuries suffered in the sport. In line with our findings, they reported $91 \%$ of injuries to occur during training and a high prevalence of injuries in the neck, fingers/hand, knees, shoulders, and elbows.

Regarding post-injury moment, participants mostly reported seeking for medical care (65\%) and receiving non-surgical treatment, including immobilization, rest, physical therapy, and medication. We found injury-related absenteeism period to be two months on average, indicating minor to moderate injuries with short and medium treatment duration. However, even short absence periods can incur loss of technique and physical fitness.

This study aims to provide a better understanding about the types of musculoskeletal injuries jiu-jitsu practitioners are exposed to and their implications. These data may help coaches and athletes to develop better techniques and educational methods to prevent and mitigate lesions.

Considering this is a questionnaire-based study, our data may not reflect the totality of injuries, since minor injuries often go unnoticed or are forgotten by patients. Moreover, participants did not report lesion type, constituting a limitation for this study. Prospective studies closely monitored by a healthcare professional may advance knowledge on this subject.

\section{CONCLUSION}

The prevalence of orthopedic injuries among jiu-jitsu practitioners is quite high (84\%). Chirodactyls, shoulder, elbow, knees, and ankles are the most affected sites, and injuries occur more frequently during training. Most practitioners receive non-surgical treatment and remain absent from sports practice for 2 months on average.

AUTHORS' CONTRIBUTIONS: Each author contributed individually and significantly to the development of this article. APN: conception and design, participants recruitment, data analysis and interpretation, writing of the article, and final approval of the submitted version; NAP: conception and design, participants recruitment, data analysis and interpretation, writing of the article, and final approval of the submitted version; GTO: conception and design writing of the article, and final approval of the submitted version; MC: conception and design, writing of the article, statistical expertise, technical support, and final approval of the submitted version.

\section{REFERENCES}

1. Souza JMC, Faim FT, Nakashima IY, Altruda CR, Medeiros WM, Silva LR. Lesions in Shotokan Karate and Jiu-Jitsu - direct trauma versus indirect. Rev Bras Med Esporte. 2011;17(2):107-10.

2. Scoggin JF, Brusovanik G, Izuka BH, van Rilland EZ, Geling O, Tokumura S. Assessment of injuries during Brazilian Jiu Jitsu competition. Orthop J Sports Med. 2014; 2(2):1-7.

3. Kreiswirth EM, Myer GD, Rauh MJ. Incidence of injury among male Brazilian jiujitsu fighters at the World Jiu-Jitsu No-Gi Championship 2009. J Athl Train. 2014:49(1):89-94.

4. Petrisor BA, Del Fabbro G, Madden K, Khan M, Joslin J, Bhandari M. Injury in Brazilian Jiu-Jitsu training. Sports Health. 2019;11(5):432-9.

5. Stephenson C, Rossheim ME. Brazilian Jiu Jitsu, Judo, and mixed martial arts injuries presenting to United States emergency departments, 2008-2015. J Prim Prev. 2018;39(5):421-35.

6. Nabhan D, Walden T, Street J, Linden H, Moreau B. Sports injury and illness epidemiology during the 2014 Youth Olympic Games: United States Olympic Team Surveillance. Br J Sports Med. 2016;50(11):688-93.

7. Kujala UM, Taimela S, Antti-Poika I, Orava S, Tuominen R, Myllynen P. Acute injuries in soccer, ice hockey, volleyball, basketball, judo, and karate: analysis of national registry data. BMJ. 1995;311(2):1465-8.

8. Caine CG, Caine DJ, Lindner KJ. The epidemiological approach to sports injuries. In: Caine DJ, Caine CG, Lindner KJ, editors. Epidemiology of sports injuries. Champaign: Human Kinetics; 1996. p. 1-13.

9. Hootman JM, Dick R, Agel J. Epidemiology of collegiate injuries for 15 sports: summary and recommendations for injury prevention initiatives. J Athl Train. 2007;42(2):311-9.
10. Pocecco E, Ruedl G, Stankovic N, Sterkowicz S, Del Vecchio FB, Gutiérrez-García C, et al. Injuries in judo: a systematic literature review including suggestions for prevention. Br J Sports Med. 2013;47:1139-43.

11. Schlutzel M, Schultzel M, Wentz B, Bernhardt M. The prevalence of injury in Kendo. Phys Sportsmed. 2016;44(1):29-33.

12. Bledsoe GH, Hsu EB, Grabowski JG, Brill JD, Li G. Incidence of injury in professional mixed martial arts competitions. J Sport Sci Med. 2006;5:136-42.

13. Nicolini AP, Carvalho RT, Matsuda MM, Sayum Filho J, Cohen M. Common injuries in athletes' knee: experience of a specialized center. Acta Ortop Bras. 2014;22(3):127-31

14. Teitz CC, Hu SS, Arendt EA. the female athlete: evaluation and treatment of sports-related problems. J Am Acad Orthop Surg. 1997;5(2):87-96.

15. Phillips LH. Sports injury incidence. Br J Sports Med. 2000;34(2):133-6.

16. Rice SG. Risks of injury during sports participation. In: Sullivan JA, Anderson SJ, editors. Care of the young athlete. Rosemont: American Academy of Orthopaedic Surgeons; 2000. p. 9-18.

17. Pastre CM, Carvalho Filho G, Monteiro HL, Netto J Jr, Padovani CR. Lesões desportivas no atletismo: comparação entre informações obtidas em prontuários e inquéritos de morbidade referida. Rev Bras Med Esporte. 2004;10(1):1-8.

18. Kochhar T, Back DL, Mann B, Skinner J. Risk of cervical injuries in mixed martial arts. Br J Sports Med. 2005;39(7):444-7.

19. McDonald AR, Murdock FA Jr, McDonald JA, Wolf CJ. Prevalence of injuries during Brazilian Jiu-Jitsu Training. Sports. 2017;5(2):39-48. 
APPENDIX 1

QUESTIONNAIRE

NAME:

AGE:

DOMINANT LIMB:

RIGHT ( ) LEFT ( )

BELT:

WHITE ( ) BLUE ( )

$\operatorname{PURPLE}($ ) BROWN ( ) BLACK ( )

WHAT IS YOUR WEEKLY TRAINING FREQUENCY?

WHAT IS YOUR COMPETITION FREQUENCY DURING THE YEAR?

DO YOU PRACTICE ANY OTHER SPORT?YES ( ) NO N $\quad$ N

IF SO, WHICH ONE?

HAVE YOU SUFFERED ANY INJURIES WHILE PRACTICING JIU-JITSU IN THE LAST 2 YEARS?？YES（）ＮＩ（）

LESION SITE:

CERVICAL SPINE

THORACIC SPINE

LUMBAR SPINE

FINGER

WRIST

ELBOW

SHOULDER

HIP

KNEE

ANKLE

PODODACTILES

TRAINING

COMPETITION OTHER

$R(\quad) L(\quad)$

$\mathrm{R}(\mathrm{)}) \mathrm{L}(\mathrm{)}$

$\mathrm{R}(\quad) \mathrm{L}(\quad)$

$\mathrm{R}(\mathrm{)}) \mathrm{L}(\mathrm{)}$

$\mathrm{R}(\quad) \mathrm{L}(\quad)$

$R(\quad) L(\quad)$

$\mathrm{R}(\mathrm{)}) \mathrm{L}($ )

$\mathrm{R}(\mathrm{)}) \mathrm{L}($ )

$\mathrm{R}(\mathrm{)}) \mathrm{L}($ )

$\mathrm{R}(\quad) \mathrm{L}($ )

$\mathrm{R}(\mathrm{)}) \mathrm{L}($ )

$R(\quad) L($ )

$\mathrm{R}(\mathrm{)} \mathrm{L}(\mathrm{)}$

$\mathrm{R}(\mathrm{)}) \mathrm{L}($ )

$\mathrm{R}(\mathrm{)}) \mathrm{L}($ )

$\mathrm{R}(\mathrm{)}) \mathrm{L}($ )

$R() L()$

$\mathrm{R}(\mathrm{)}) \mathrm{L}($ )

$R(\quad) L(\quad)$

$\mathrm{R}(\mathrm{)}) \mathrm{L}($ )

$R() L()$

$\mathrm{R}(\quad) \mathrm{L}()$

$\mathrm{R}(\quad) \mathrm{L}($ )

$\mathrm{R}(\quad) \mathrm{L}(\quad)$

$\mathrm{R}(\quad) \mathrm{L}($ )

$\mathrm{R}(\mathrm{)}) \mathrm{L}(\mathbf{)}$

$\mathrm{R}(\mathrm{)}) \mathrm{L}($ )

$R(\quad) L(\quad)$

$R($ ) $L($ ()

$R(\quad) L(\quad)$

$R() L()$

$R() L()$

DID YOU LOOK FOR MEDICAL CARE? $\quad$ YES ( ) NO ( )

RECEIVED TREATMENT:

SURGERY（） PHYSICAL THERAPY（） IMMOBILIZATION（） MEDICATION（）

FOR HOW LONG WERE YOU ABSENT FROM SPORTS PRACTICE?

ONCE YOU RETURNED TO THE SPORT PRACTICE, WERE YOU AT THE SAME LEVEL AS BEFORE THE INJURY? 